\title{
امتداد نطاق التأمين البحري على البضائع لضمان الأخطار غير البحرية
}

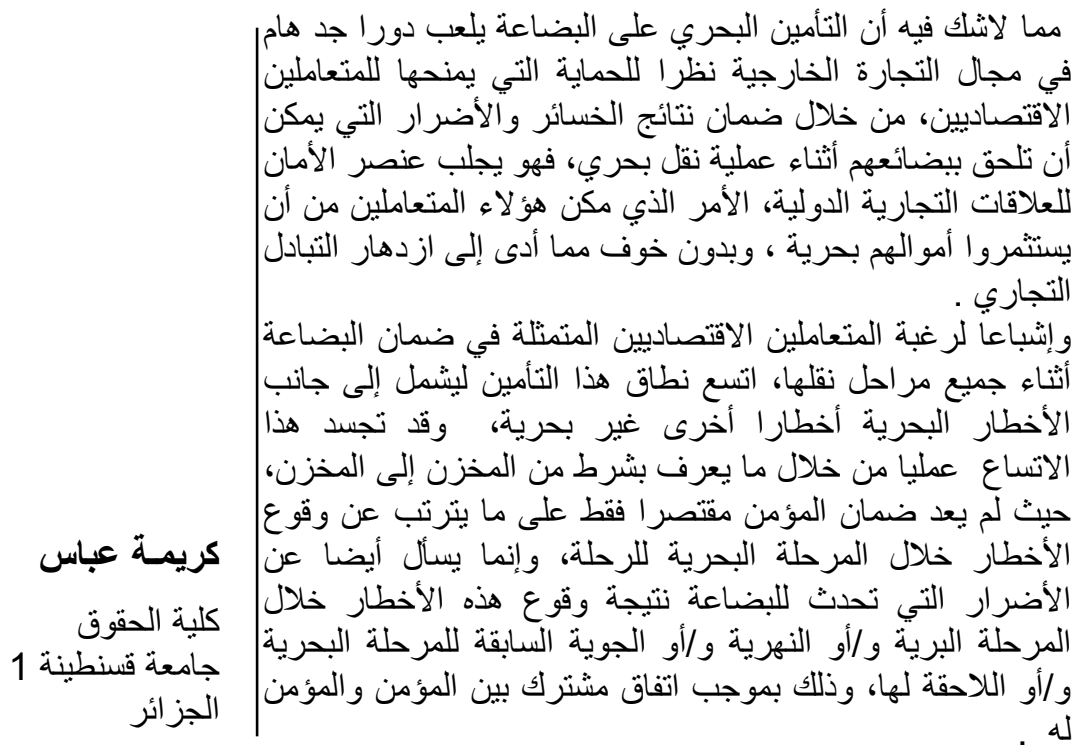

\begin{abstract}
Undoubtedly, the marine cargo insurance plays an important role in the field of foreign trade because of the

مقدمة warranty it provides to economic actors against damages and losses that may لـعلد التأمين البحري منذ قرون بعيدة affect their goods during maritime operations. It provides secure هيئة في خدمة التجارة الدولية، وهو البح حاليا

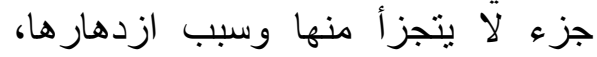

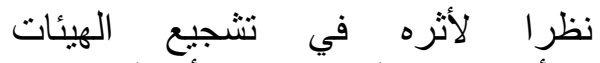
والأشخاص على أستثمار أموالهي فئره فيها،

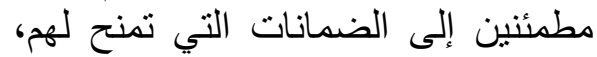
والتعويضات التي يمكنهم استيفائها نتيجة

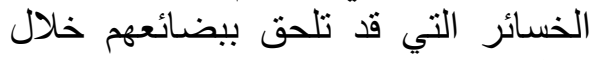
عملية نقلها والتي تتم بعيدا عن رقابتهم international trade and freedom of investment that encourage prosperous trade. To satisfy the needs of trade transactions, the insurance companies extended the field of guarantee of the contract to non maritime risks including the store-to-store condition of cargo insurance when the insured goods are possibly the object of a ground, river, or air transport, preliminary and/or و و إثر افهم complementary to maritime transport, according to a contracted mutual agreement between insurer and insured.
\end{abstract}




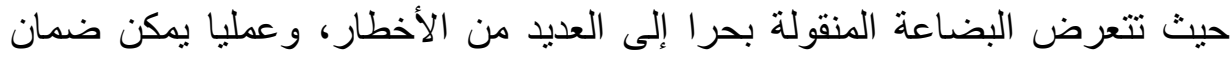

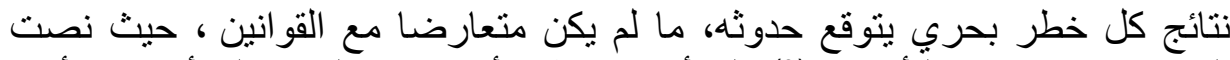

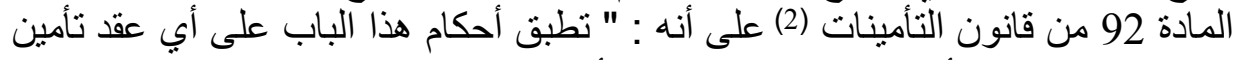

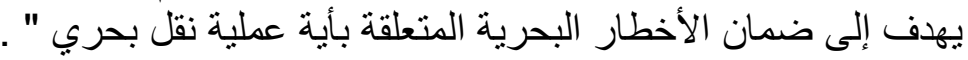

إذ اعتمد المشرع من خلال النص المذكور في تعريفه لعقد التأمين البحري على النى الني

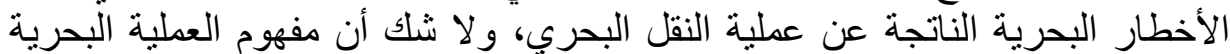

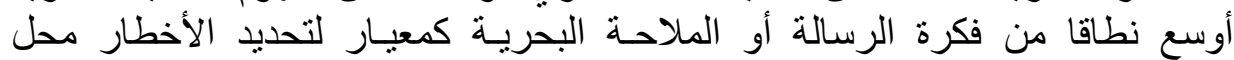

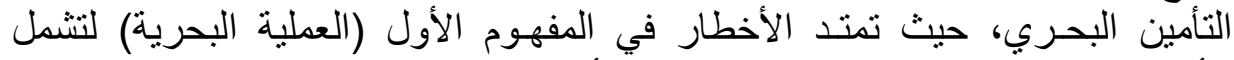

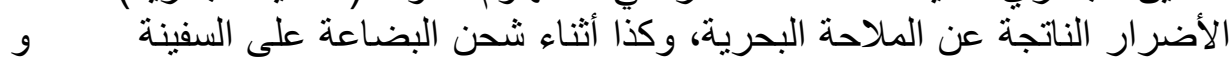

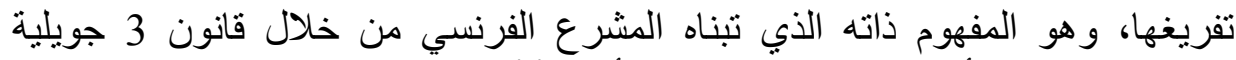

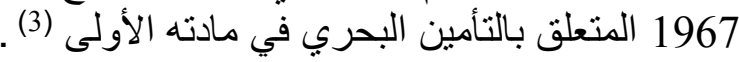

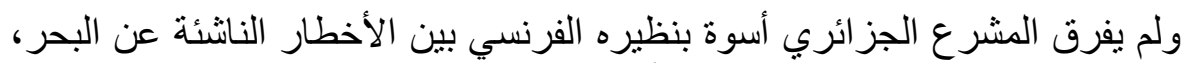

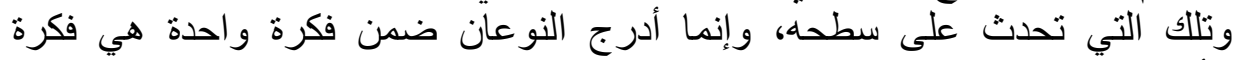

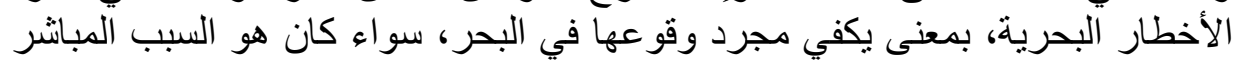

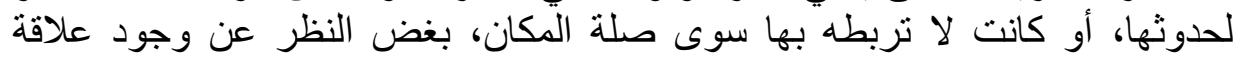

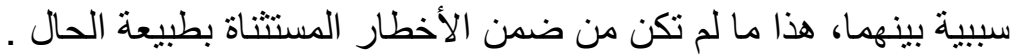

كما لم يقتصر المشرع الجزائري الخطر محل التأمين البحري على البه الأخطار

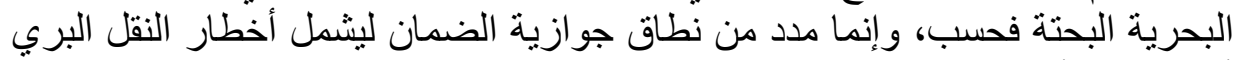

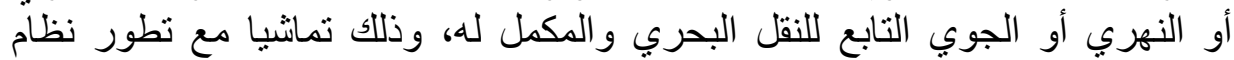

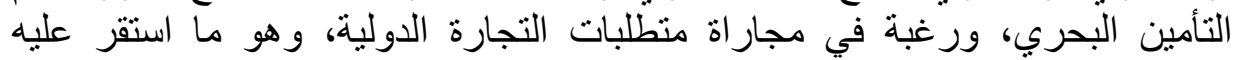
القضاء الفرنسي وناد به الفقه .

وإن شمل عقد التأمين البحري على البضاعة إضافة إلى الأخطار البحرية أخطارا

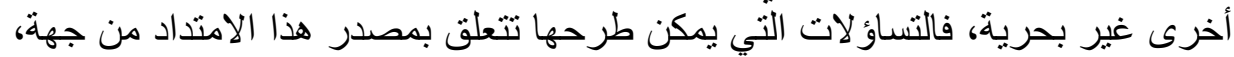

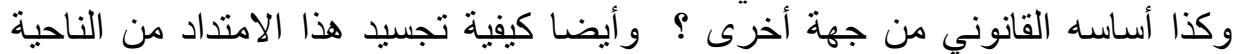
العملية ؟ وإن كانت هناك عو امل مؤثرة فيه ؟ ذلك ما سنحاول الإجابة عنه من خلال

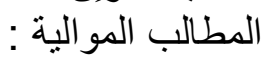

\section{المطلب الأول}

\section{نظرية امتداد نطاق التأمين البحري على البضائع لضمان الأخطار الغير بحرية}

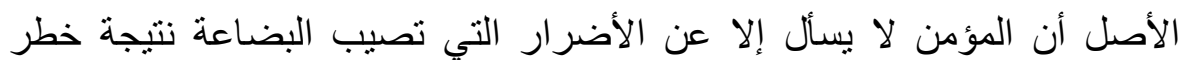

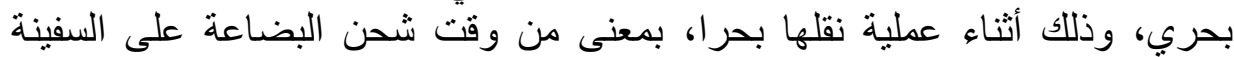

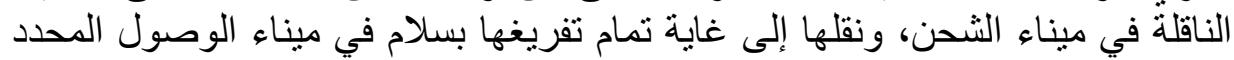


غير أنه يجوز أن يمتد الضمان ليشمل أخطارا غير بحرية، بمعنى تلك التي يمكن التهاه

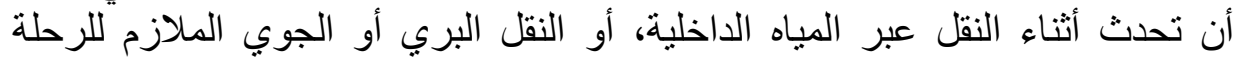

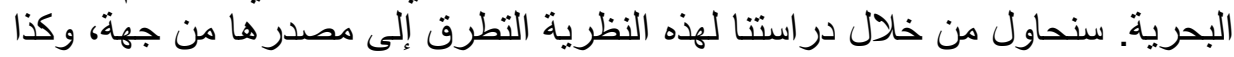
البحث عن أساسها القانوني من جهة أخرى.

\section{القرع الأول}

\section{مصدر امتداد نطاق التأمين البحري على البضائع لضمان الأخطار الغير بحرية}

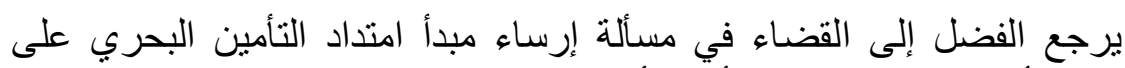

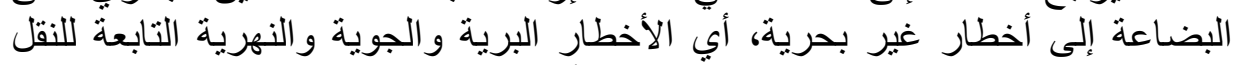

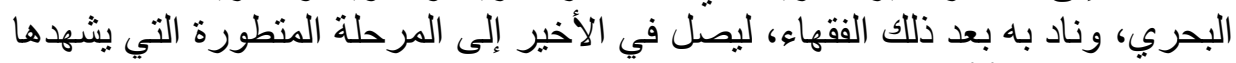

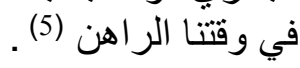

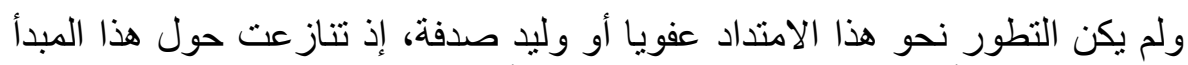

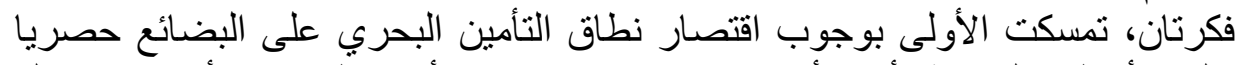

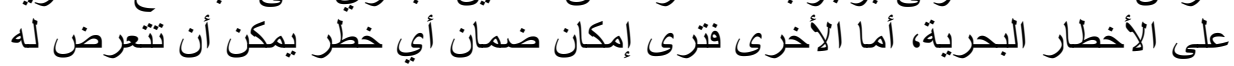

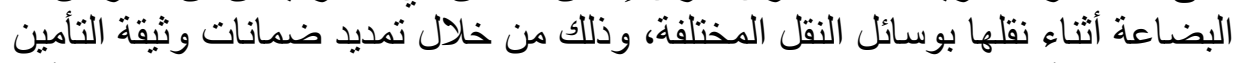

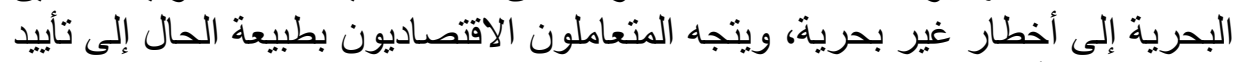

هذه النظرة الأخيرة (6) الخطار (1)

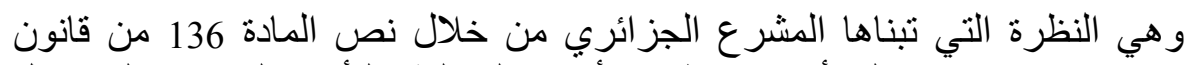

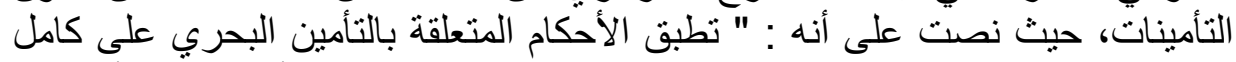

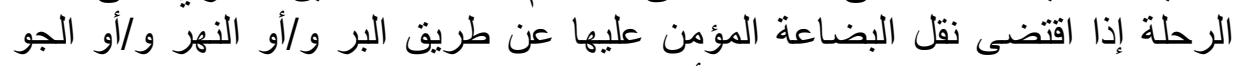

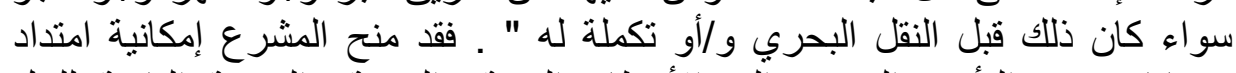

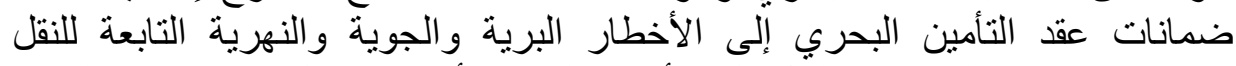

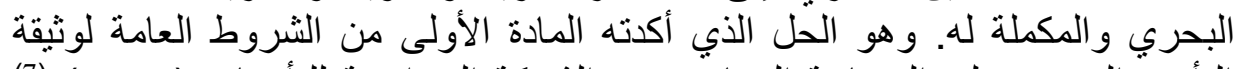

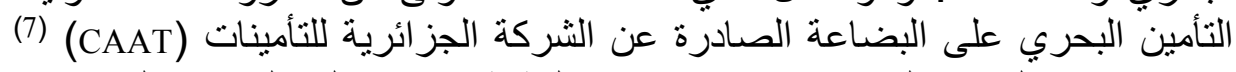

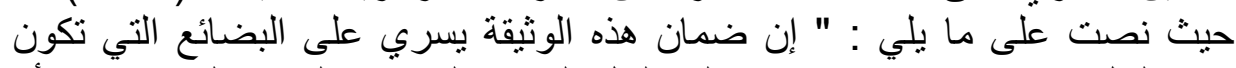

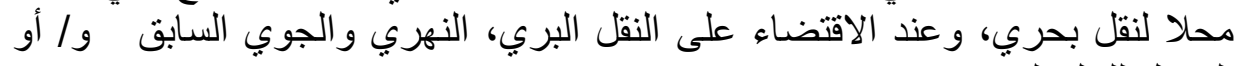

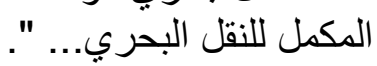

وتجدر الإشارة إلى أن امتداد التأمين البحري على كامل الرحلة عند اقتضاء نقلها

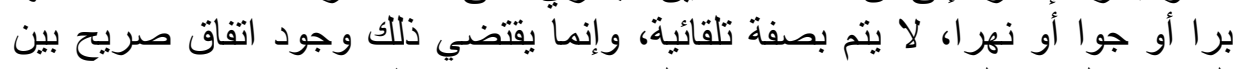

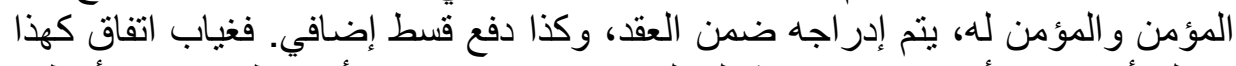

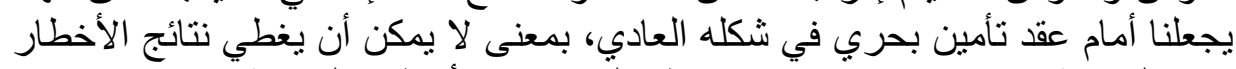

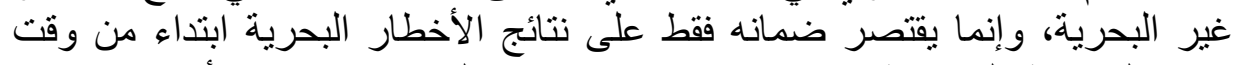

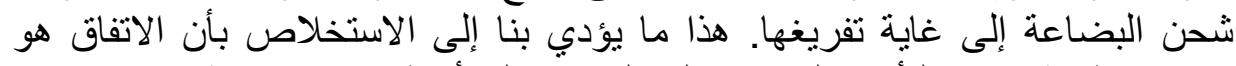
مصدر نظرية امتداد التأمين البحري على البضي هذائع إلى أخطار غير بحرية. 
كما أكد المشرع من خلال نص المادة السابق الإشارة إليه ( المادة 136 من قانون

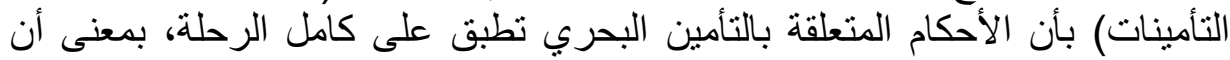

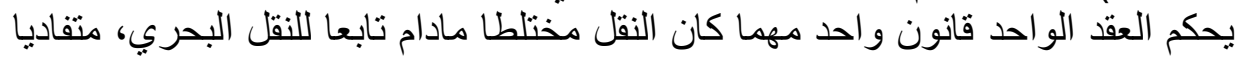
بذلك تجزئة التصرفات التي تعتبر في ذهن المتعاقدين كلا متر ابطا، وذلك متى كان التيان

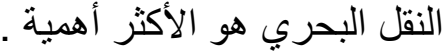

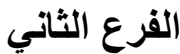

الأخطار الغير بحرية القاني لنظرية امتداد نطاق التأمين البحري على البضائع لضمان

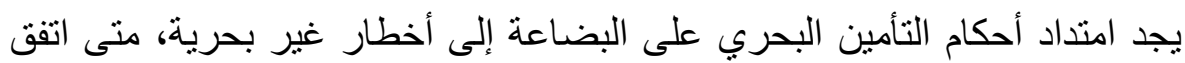

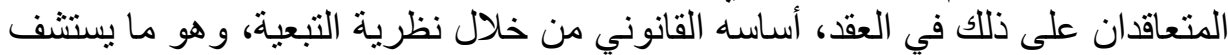

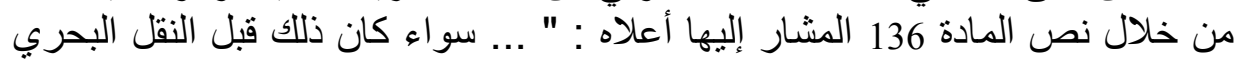

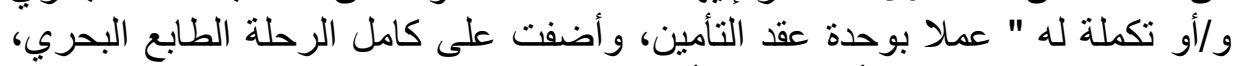

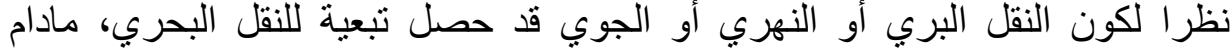

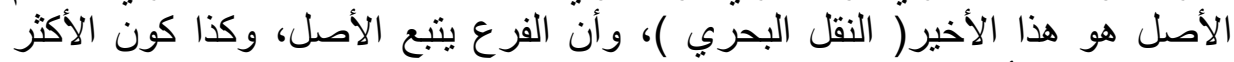

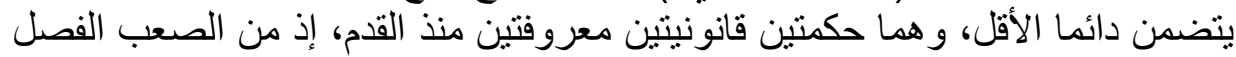

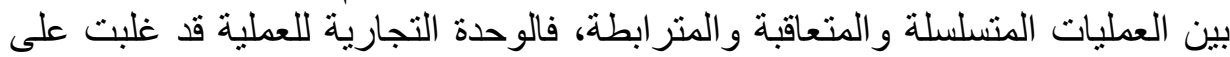

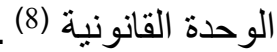

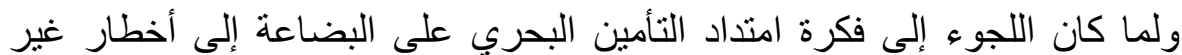

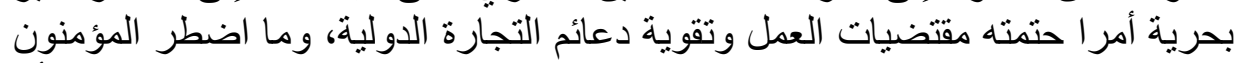

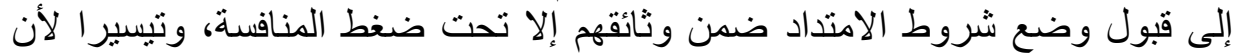

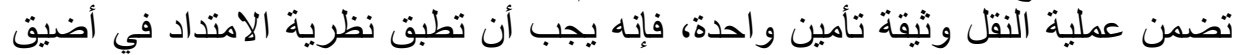

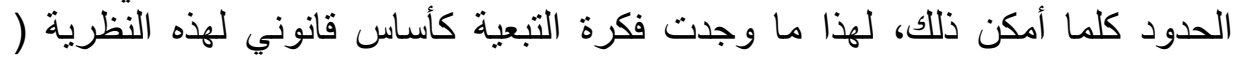

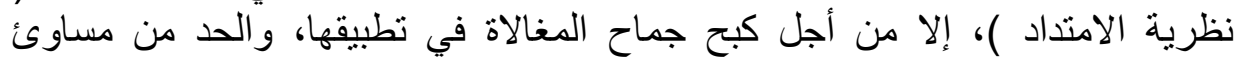

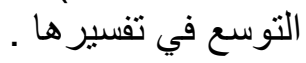

لهذا فإن فكرة التبعية، وإن كانت تعتبر الأساس القانوني لثرط التئ إنداد التأمين

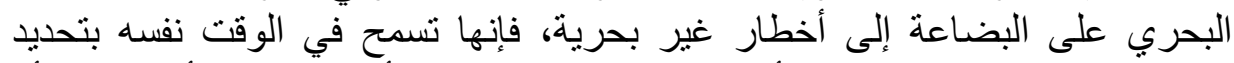

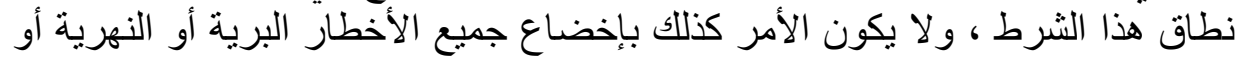

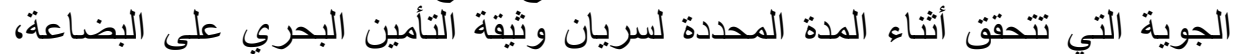

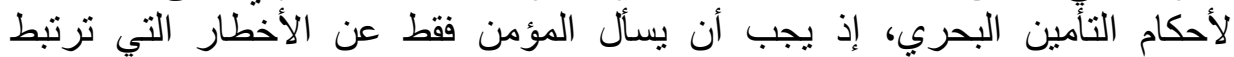

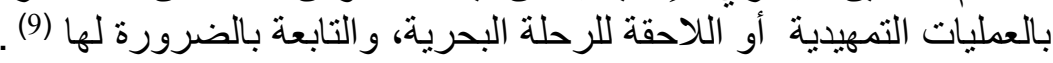

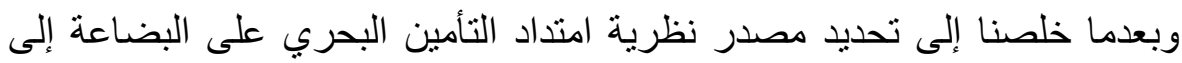

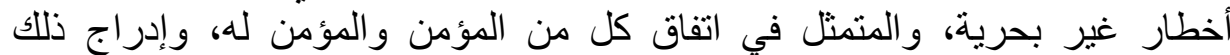

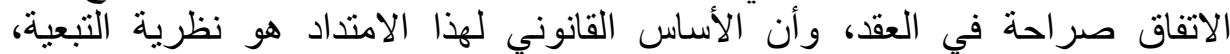


سنحاول تتاول أهم الصور العملية لهذا الامتداد، وهو ما سنراه من خلال المطلب

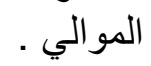

$$
\text { المطلب الثاني }
$$

التأمين من المخزن إلى المخزن كأحد أهم الصور العملية لنظرية امتداد نطاق المقائ التأمين البحري على البض من المخن إلى

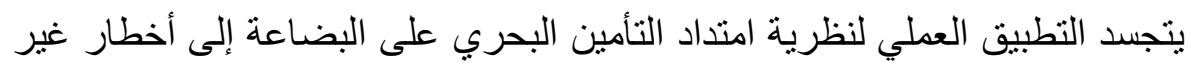

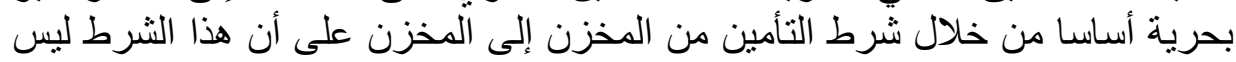

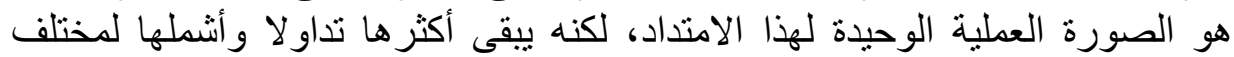

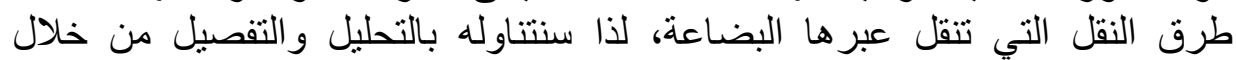

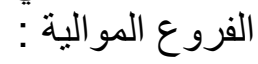

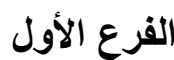

\section{نطاق شرط من المخزن إلى المخزن}

لما كانت الحماية التي تقدمها وثثقة التأمين البحري على البضائع في شكلها العادي

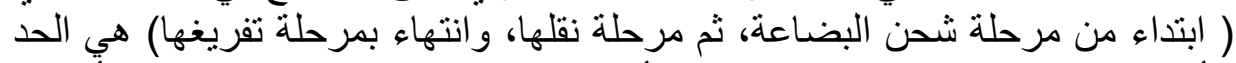

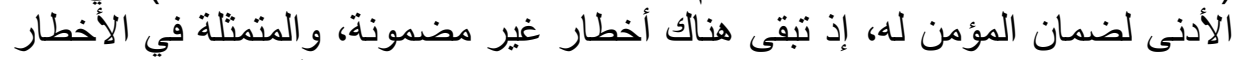

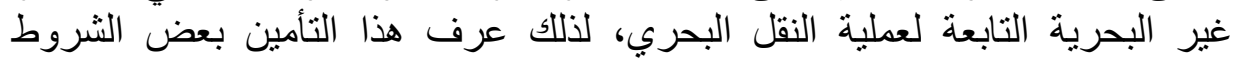

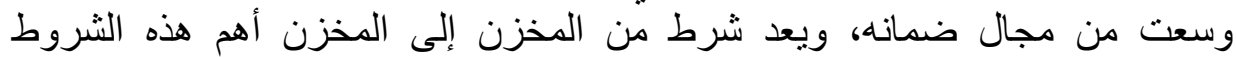

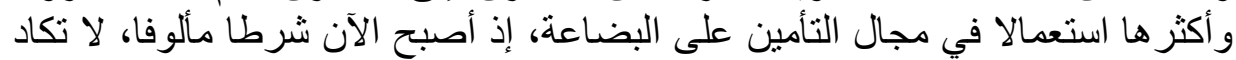

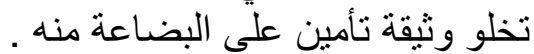

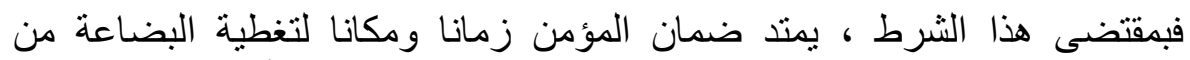

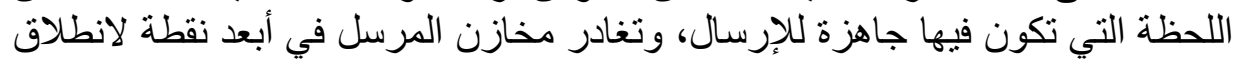

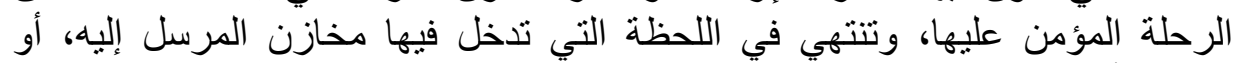

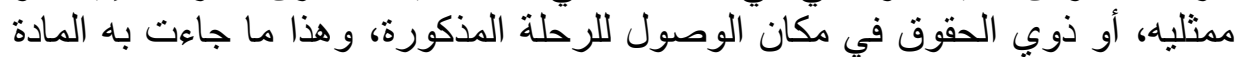
9 من الثروط ألعامة .

فالجديد الذي أتى به هذا الثرط يتمثل في أن البضاعة تكون مغطاة قبل استلام

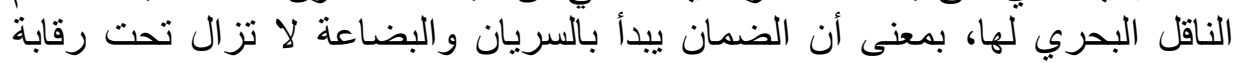

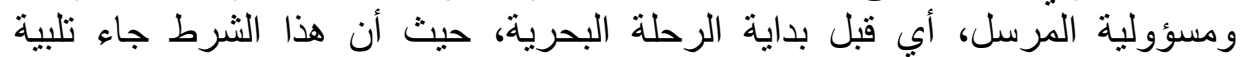

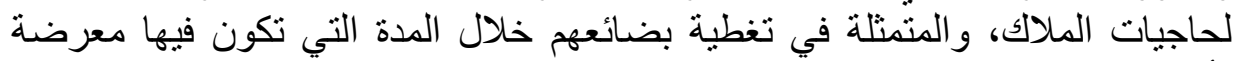

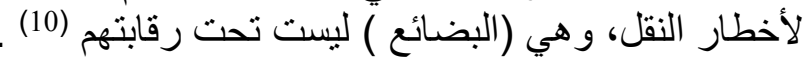

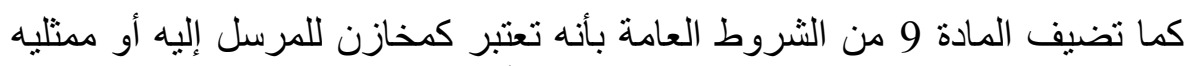

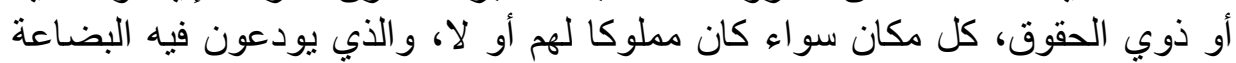

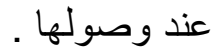


غير أنه إذا وصلت البضاعة المؤمن عليها إلى مكان الوصول للرحلة المضمونة، إنها

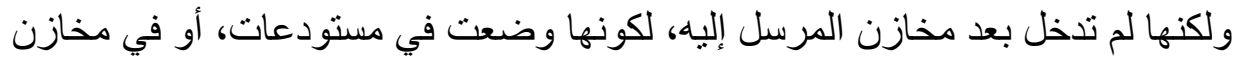

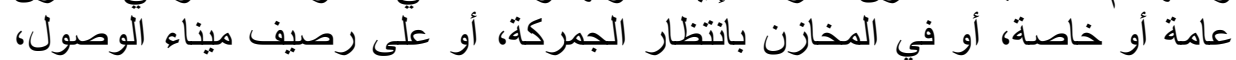

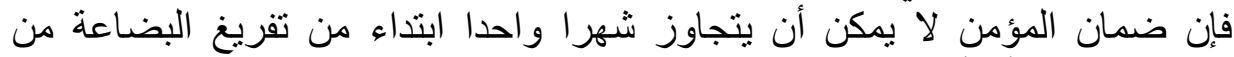

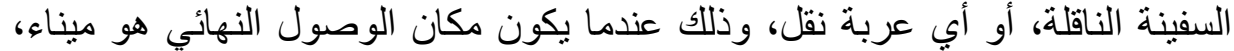

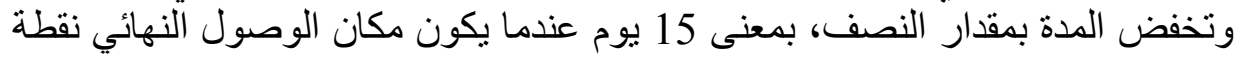

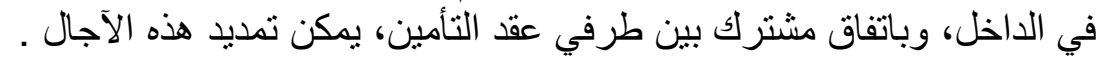

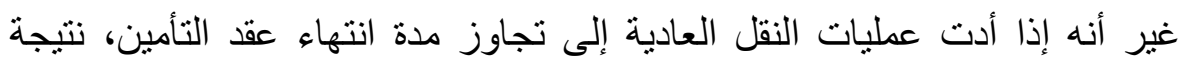

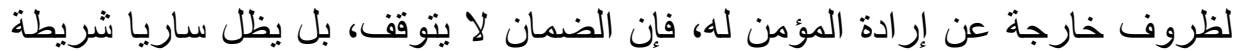

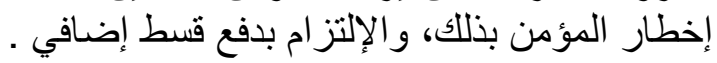

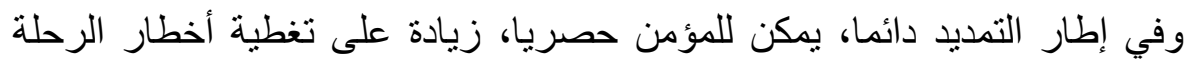

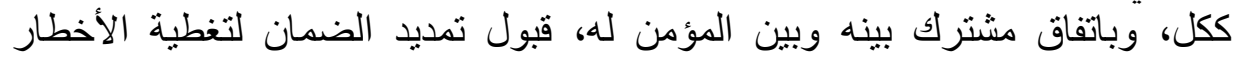

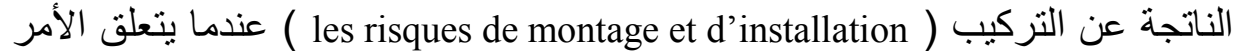

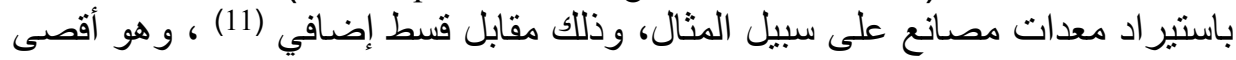

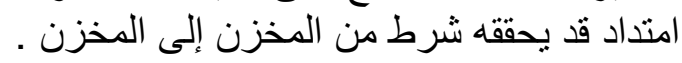

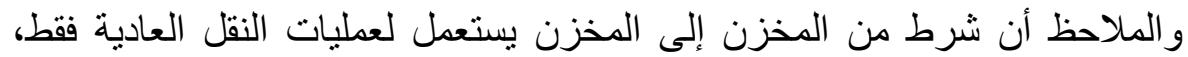

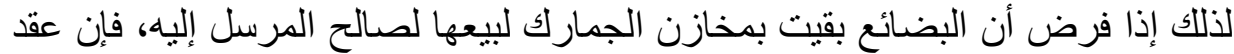

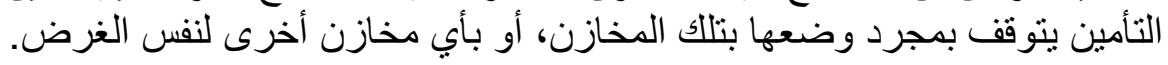
وتجدر الإشارة إلى أن شرط من المخزن إلى المخزن لا يضيف جديدا إلى الأخطار

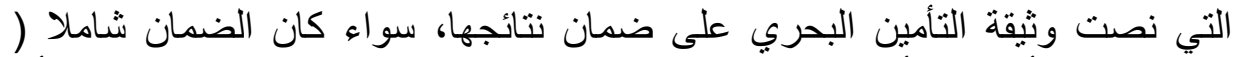

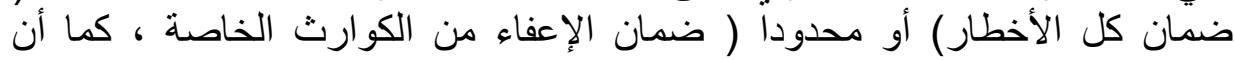

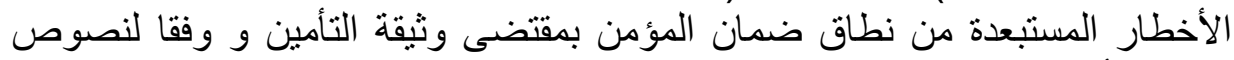

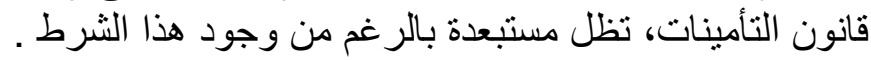

فثرط من المخزن إلى المخزن لا يغير إذا من نطاق ضمان الأن المؤمن، كما لا يغير

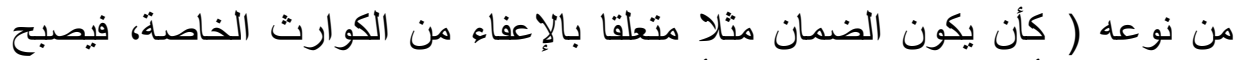

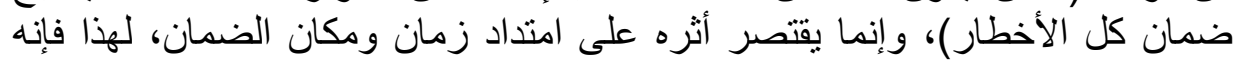

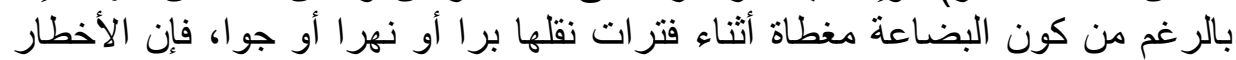

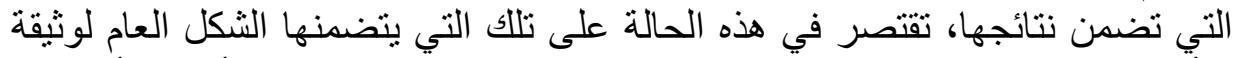

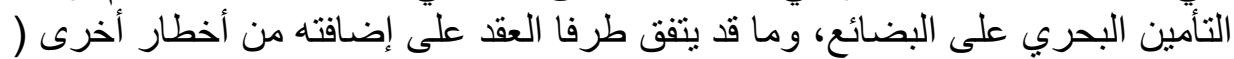

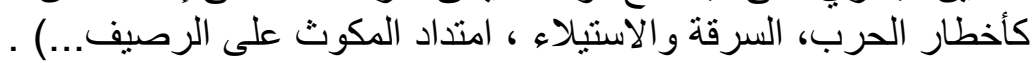

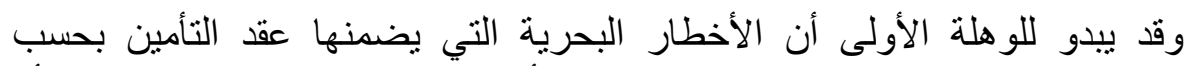

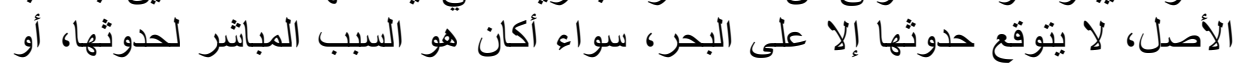

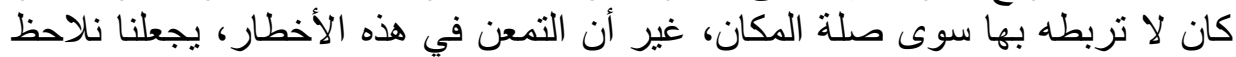


بأنه فيما عدا أخطار البحر (الغرق ، التخلي ، المساهمة في الخسائر المشتركة)،

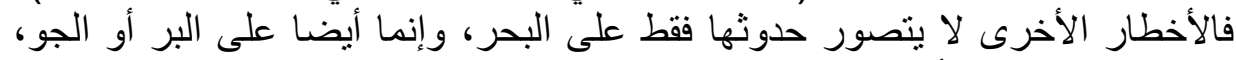

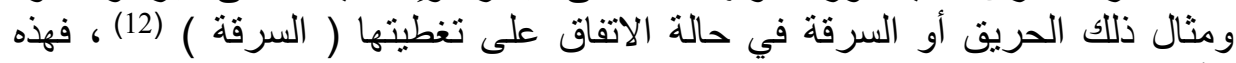

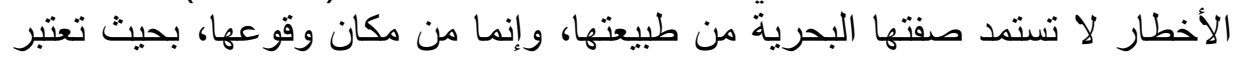

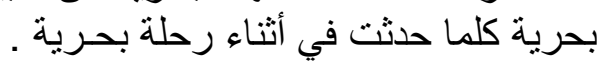

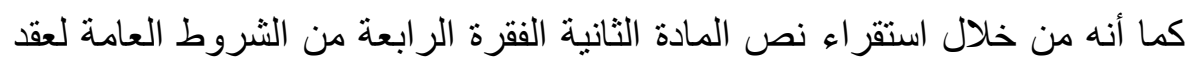

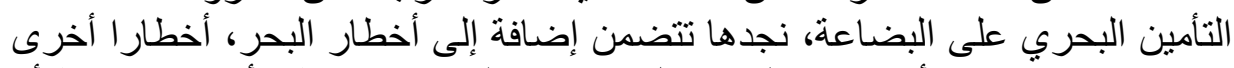

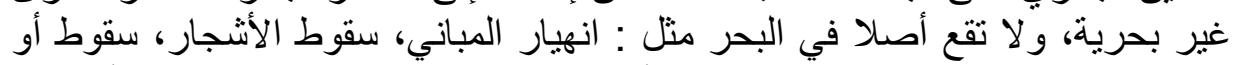

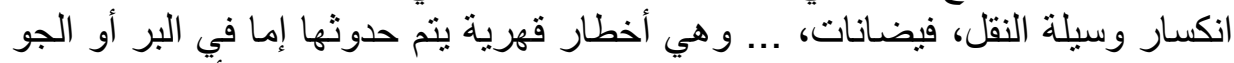

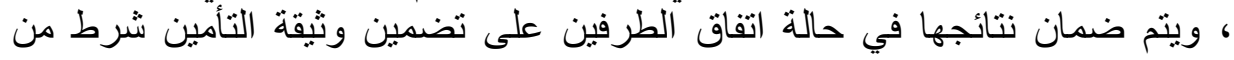
المخزن إلى المخزن .

\section{الفرع الثاني}

العوامل المؤثرة في سريان وثيقة التأمين بشرط من المخزن إلى المخزن

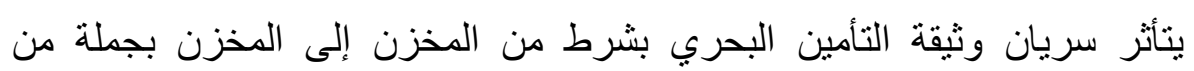

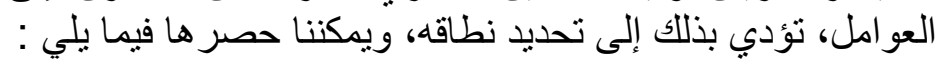

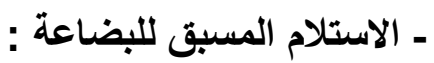

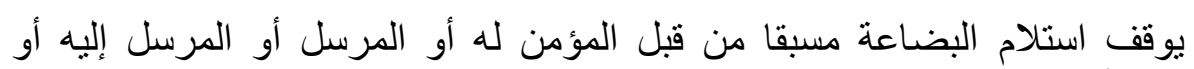

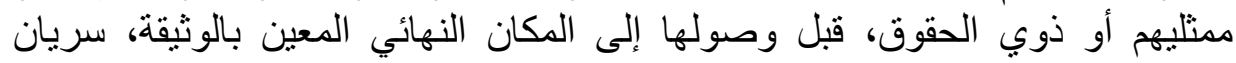

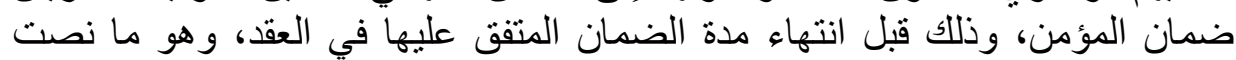

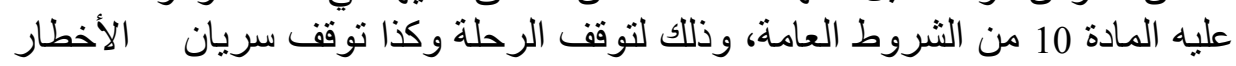

\section{ـ تغيير الطريق:}

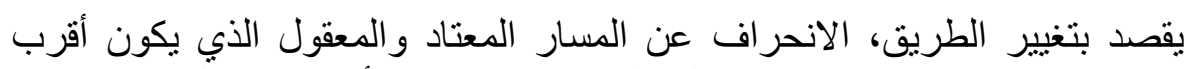

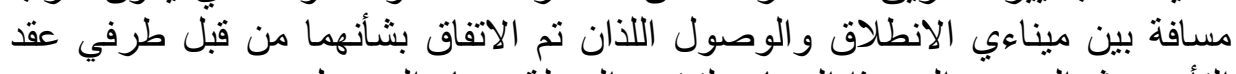

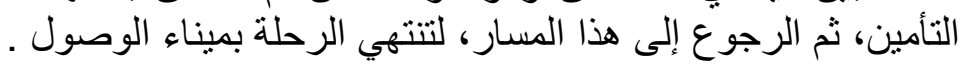

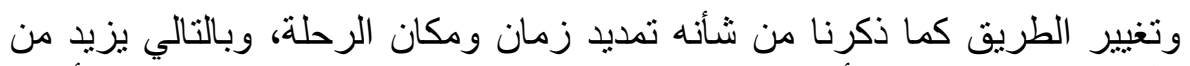

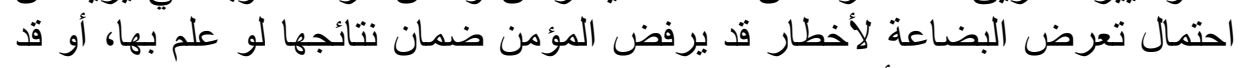

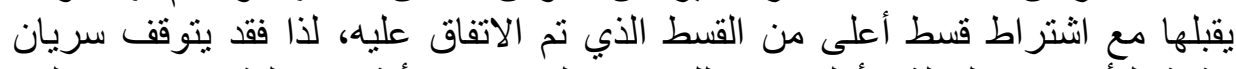

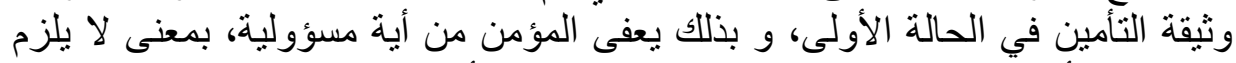

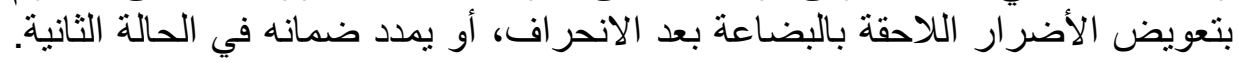

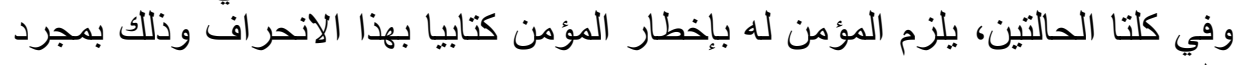


غير أن التغيير الاضطراري للطريق، بفعل قوة قاهرة، أو نتيجة وقوع التون حادث

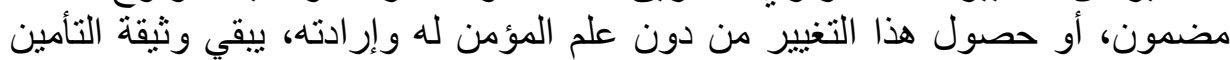

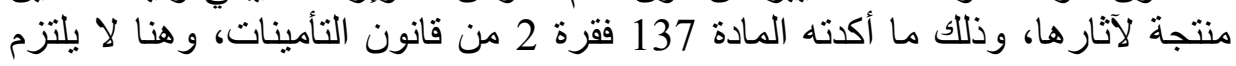

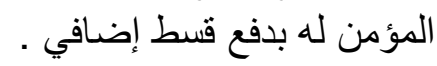

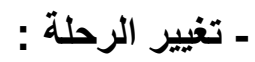

تحدد الرحلة بميناء الإقلاع لتنتهي بميناء الوصول، والتأمين على البضاعة يسري

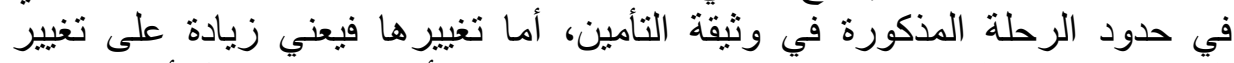

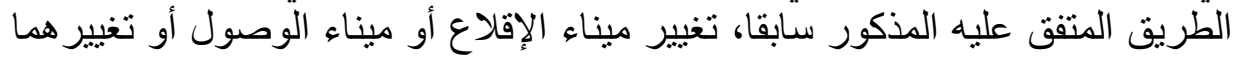

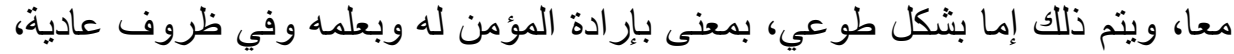

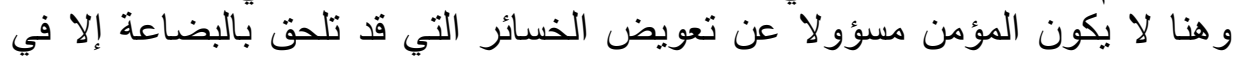

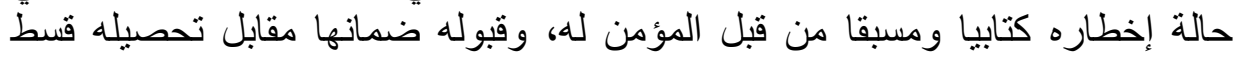
إضنافي .

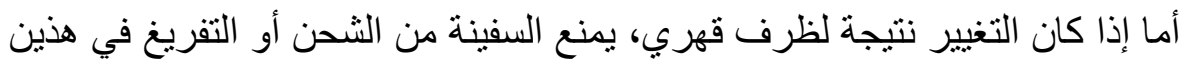

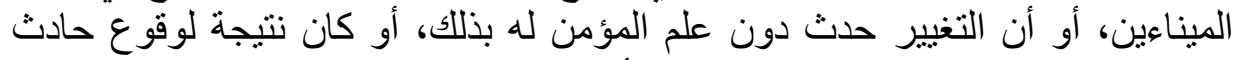

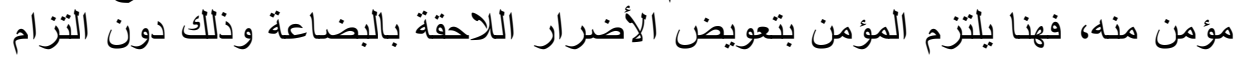

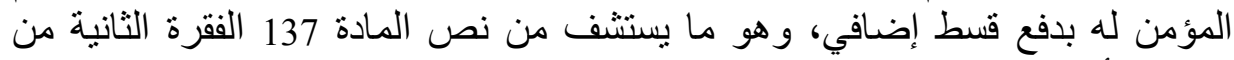
قانون التأمين . ل الهون

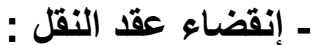

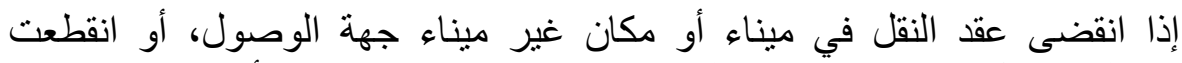

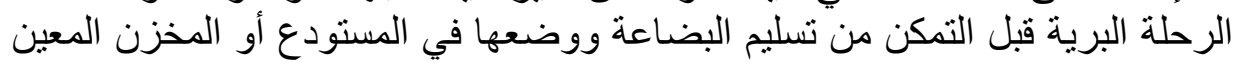

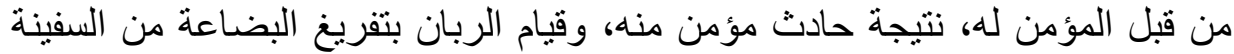

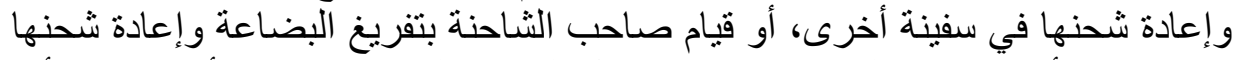

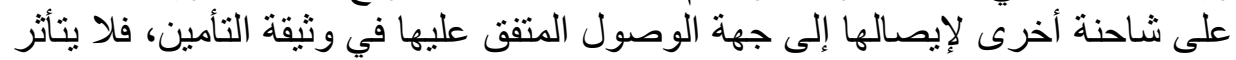

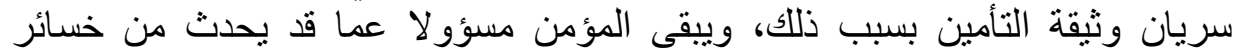

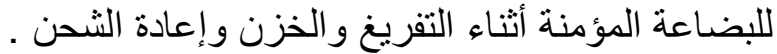

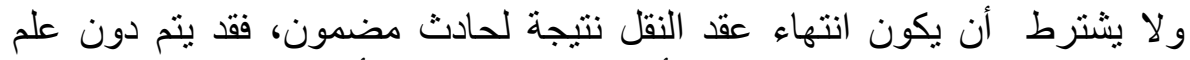

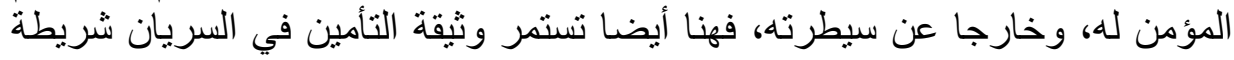

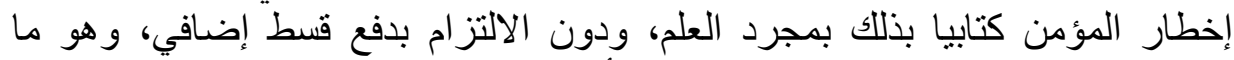

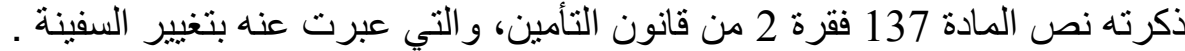

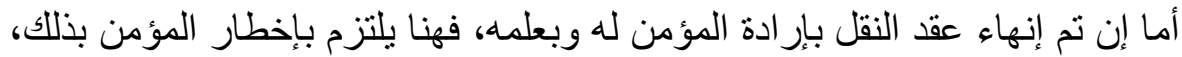
وتبقى للمؤمن الحرية في استمرار الضمان مقابل قسط إضافي، أو أو إيقافه . 
إن السفينة ووسائل النقل الأخرى يجب أن تتفذ رحلتها وفق مسارها المحدد

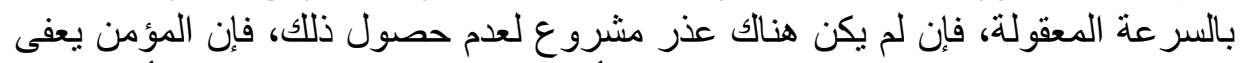

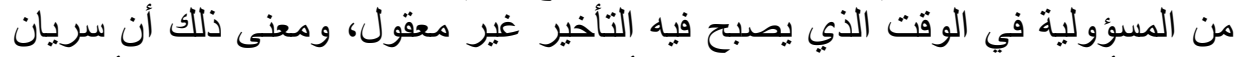

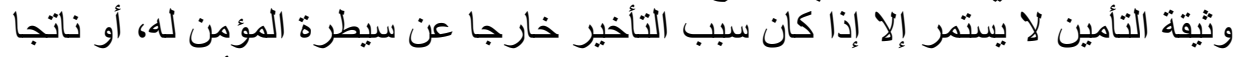

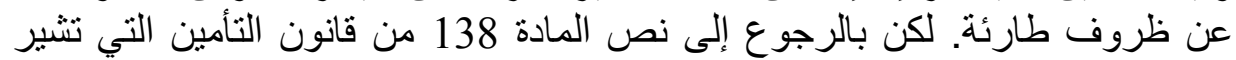

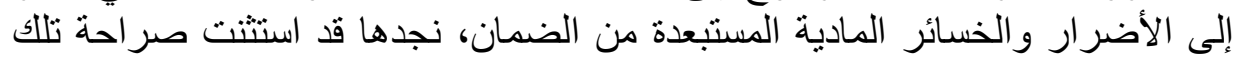

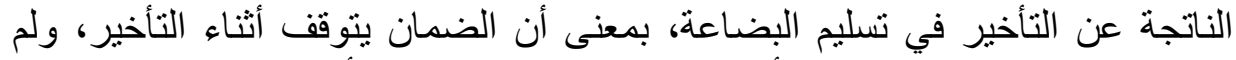

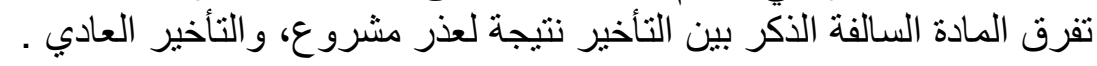

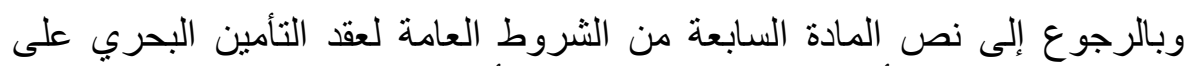

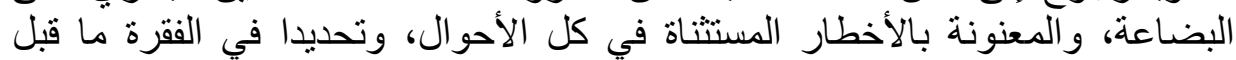

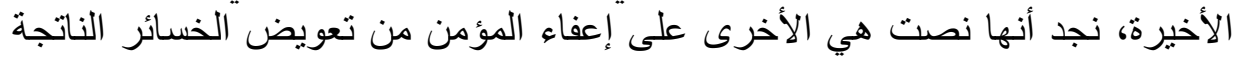

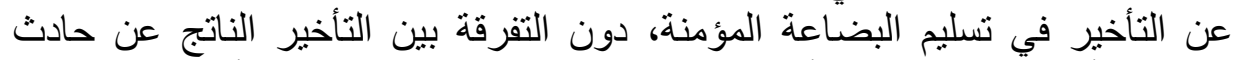

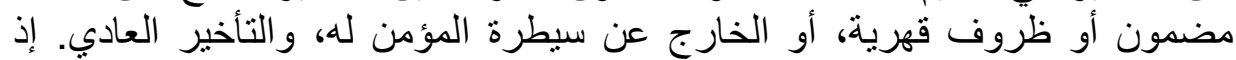

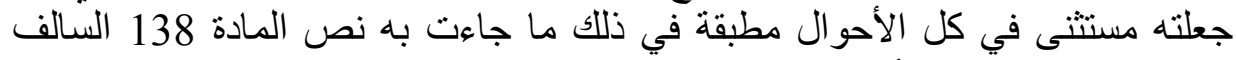

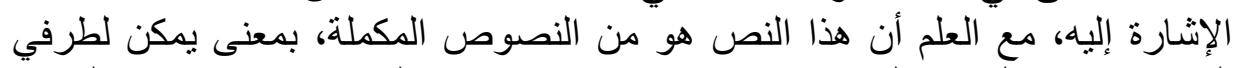

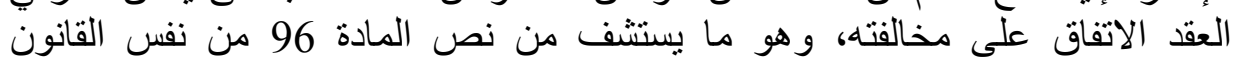

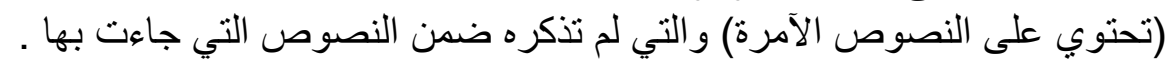

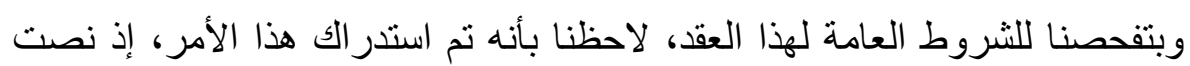

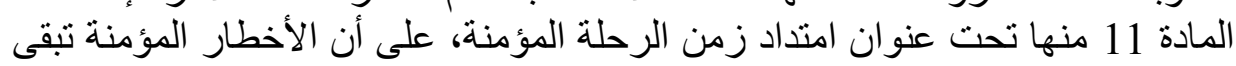

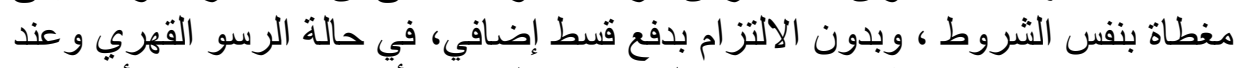

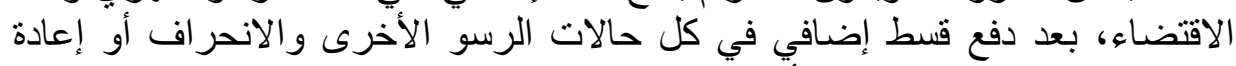

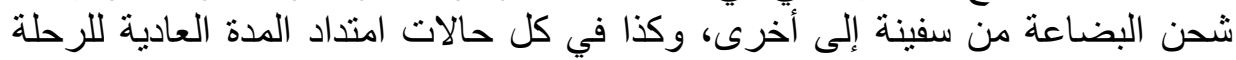

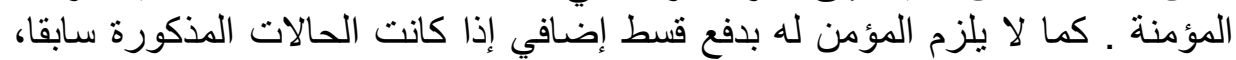

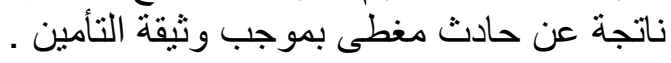

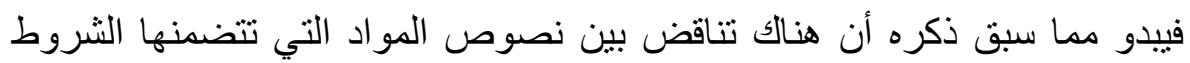

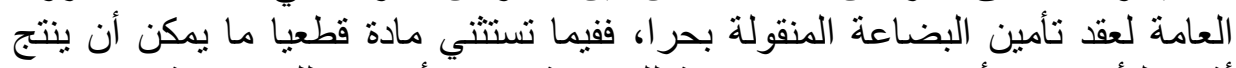

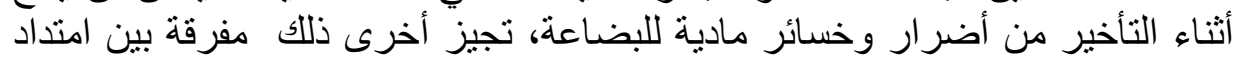

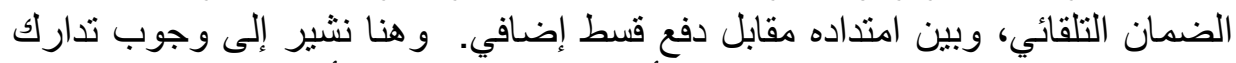

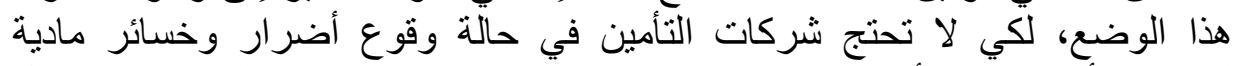

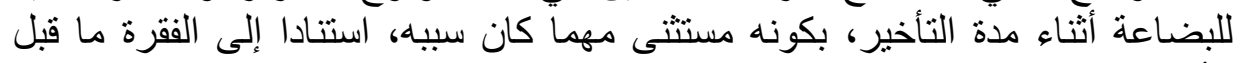

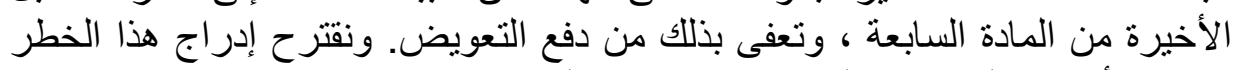

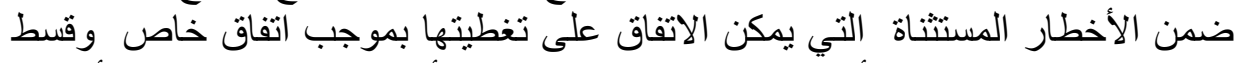

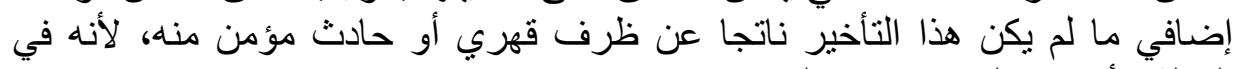

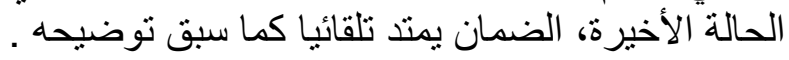




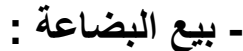

إذا بيعت البضاعة وهي لا تزال محملة على السفينة، ولم يتم الاتفاق بين البائع

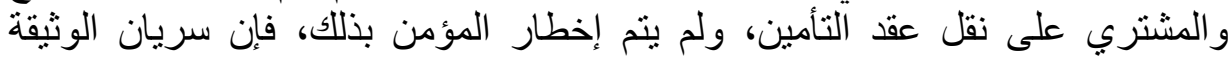
يتوقف، وينقضي بذلك العقد بعد تفريغ البضاعة من السفينة الناقلة، وتحميلها في في التيان و اسطة نقل المشتري، بمعنى من وقت تسليم الثيء المبيع، وخروج البضع البضاعة من ملكية

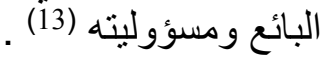

وتجدر الإشارة إلى أن العوامل المذكورة أعلاه ، تؤثر أيضا على عقد النقل البري

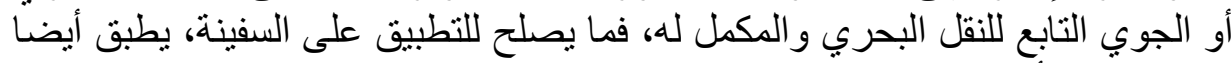

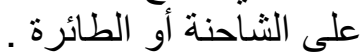

إن ما يلاحظ على كل العوامل المذكورة أعلاه، وباستثناء العامل الأول، أنها تمثل

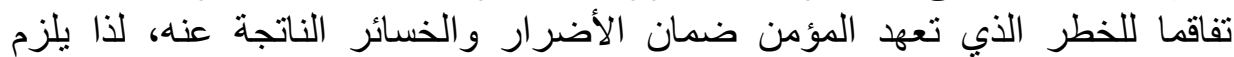

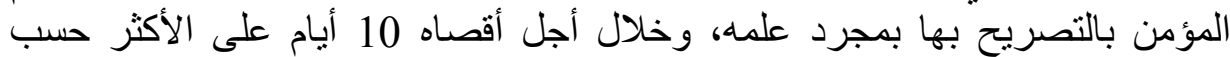

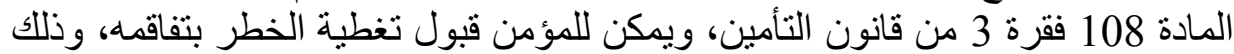

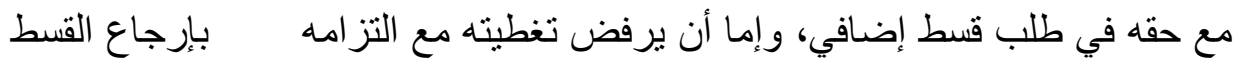

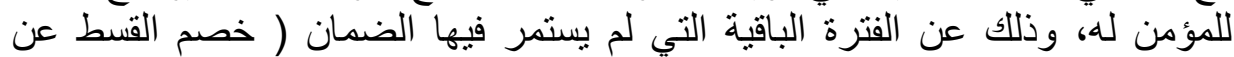
الفترة التي كان فيها الضمان ساريا قبل تفاقم الخطر، و إرجاع الباقي للمؤمن لهل) .

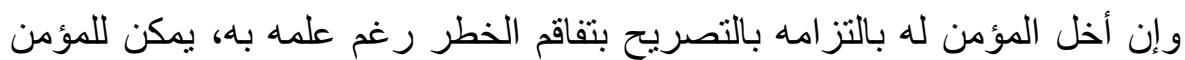

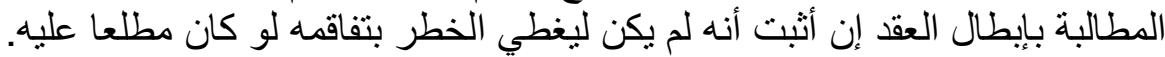

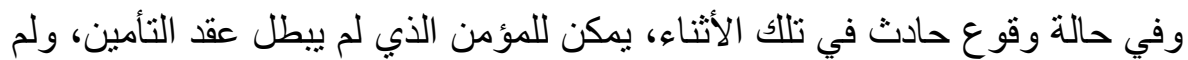

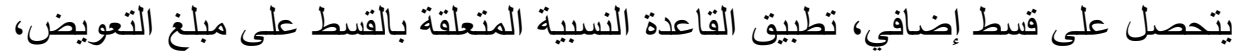

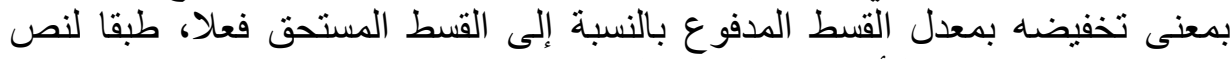
المادة 109 من قانون التأمين، وذلك كما يلي :

$$
\text { مبلغ التعويض الذي يلزم المؤمن بأدائه = }
$$

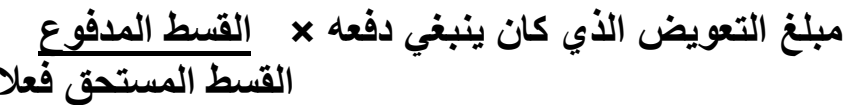

\section{الخاتـمة}

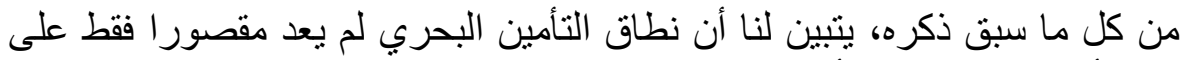

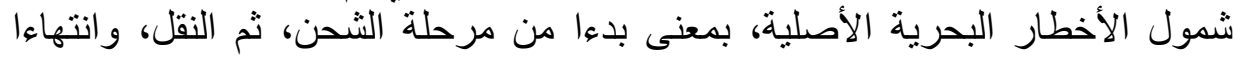

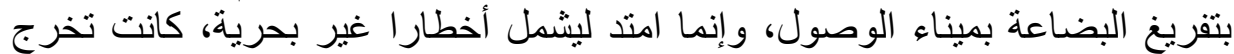
بطبيعتها من نطاق هذا التأمين. إذ أصبح يشمل الأخطار النهرية و أو أو البرية وأوانية

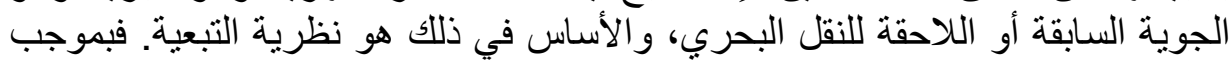

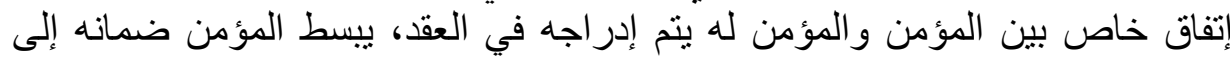




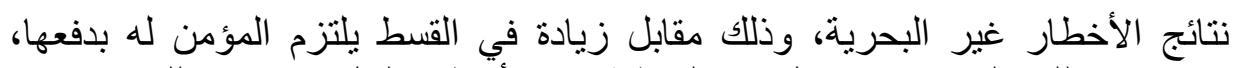

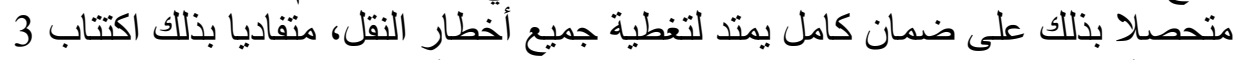

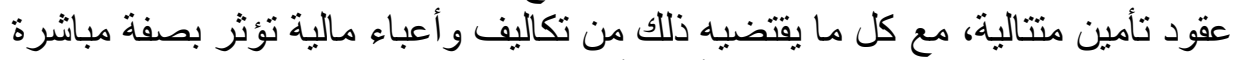

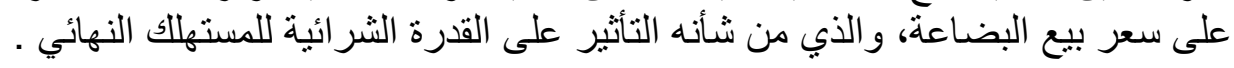

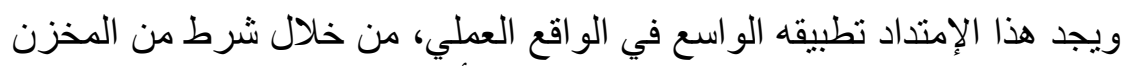

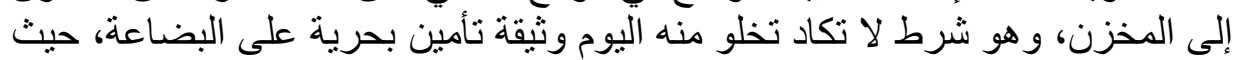

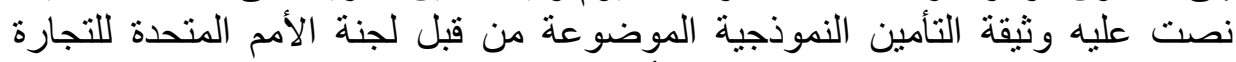

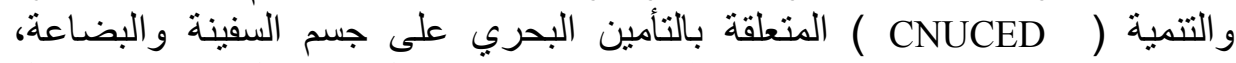

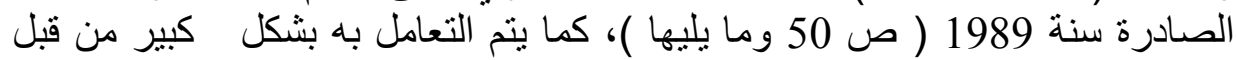

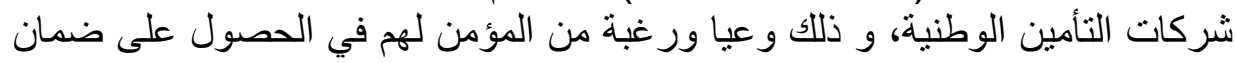

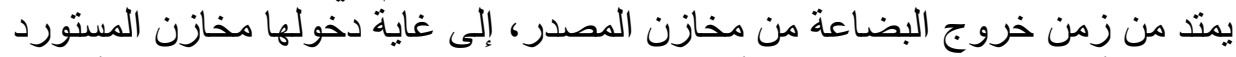

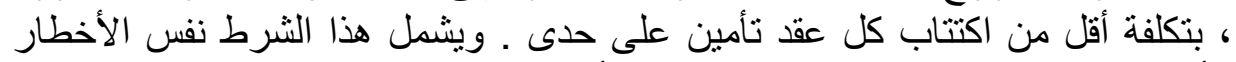

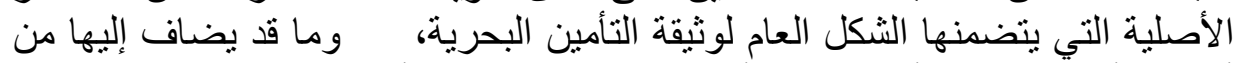

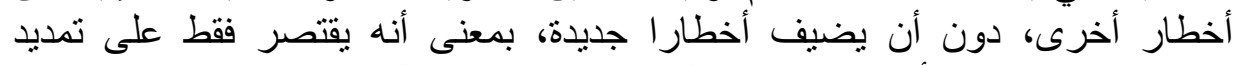

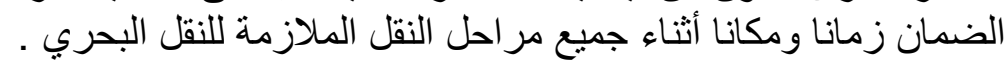

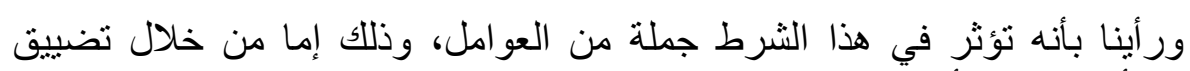

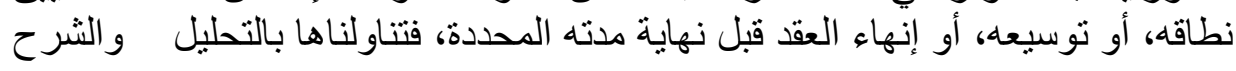

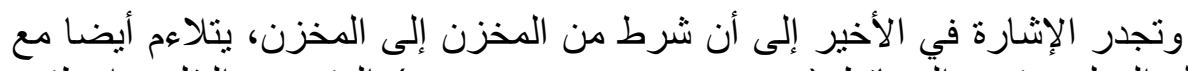

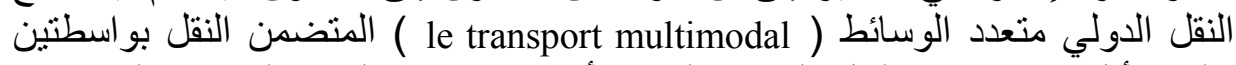

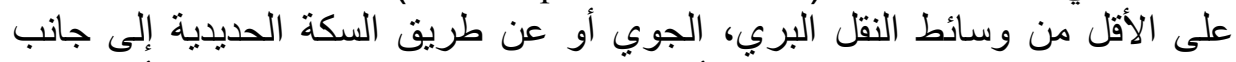

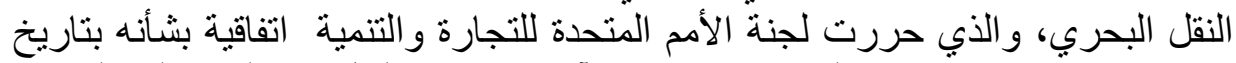

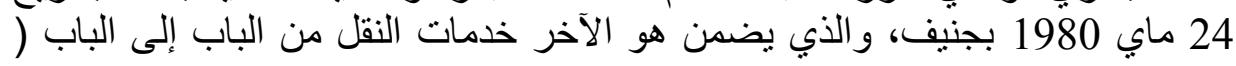
. ( transport de bout en bout

1- منى محمد عمار، العلي السيد الديب، التأمين البحري، الجزء الأول، جامعة القاهرة، كلية

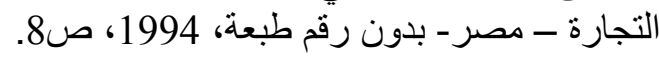

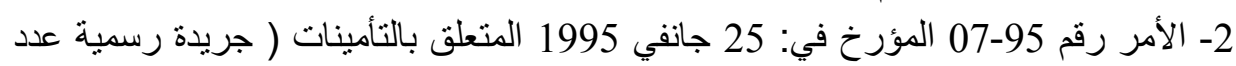

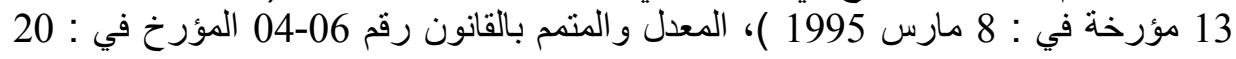

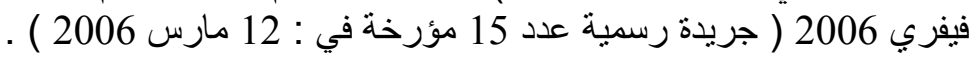


3- علي بن غانم، التأمين البحري وذاتية نظامه القانوني، ديوان المطبوعات الجامعية، بن

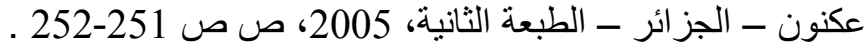

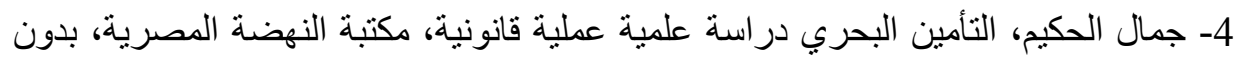

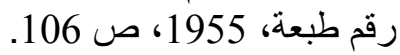

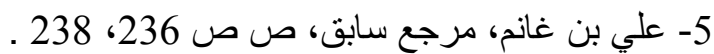

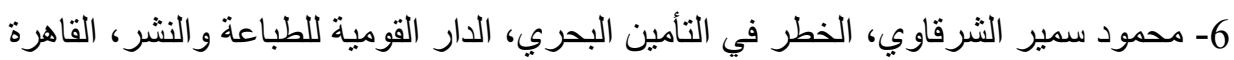

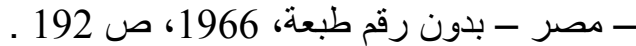

7- Les conditions générales de la Compagnie Algérienne d'Assurances (CAAT). Police d'assurance maritime sur faculté. Visa M.F.N ${ }^{\circ} 15$ du 16/03/1998. p.2.

$$
\text { 9- 8- علي بن غانم، مرجع سابق، صمير الثرقاوي، مرجع سابق، ص ص ص } 2037 \text { ، } 204 \text { ـ } 203
$$

10- Othmane BENFADHEL. L'assurance transport de magasin à magasin. Article publié dans la revue mensuelle algérienne : le phare $\mathrm{n}^{\circ} 56$. Décembre 2003. p. 43.

11- Othmane BENFADHEL. Les assurances maritimes et transports. Article publié dans la revue mensuelle algérienne : le phare $\mathrm{n}^{\circ} 6$. Octobre 1999. p.23.

12- نشبر إلى أن خطر السرقة والاستيلاء غير مغطى بموجب وثيقة التأمين البحري على البى

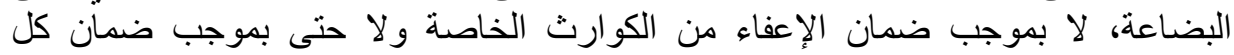

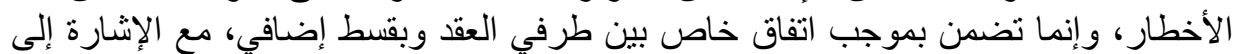

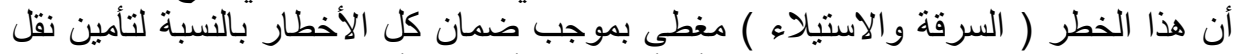

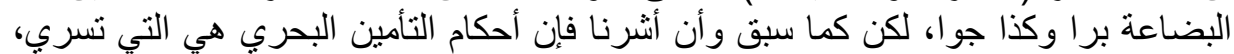

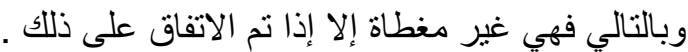

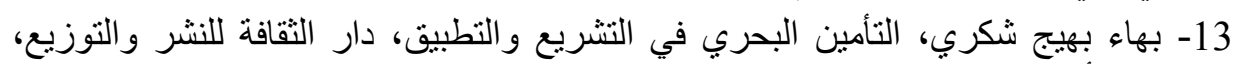
عمان - الأردن- بدون رقم الطبعة، 2009، صين صي لـ 643 ـ

\section{قائمة المراجع

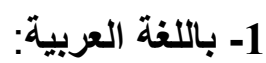

- الأمر رقم 07-95 المؤرخ في: 25 جانفي 1995 المتعلق بالتأمينات، المعدل و المتمم

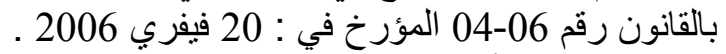

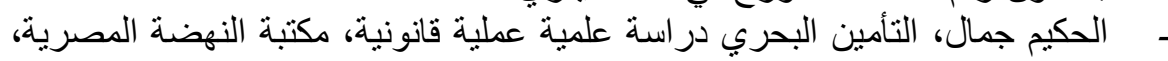

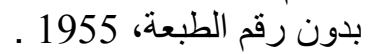




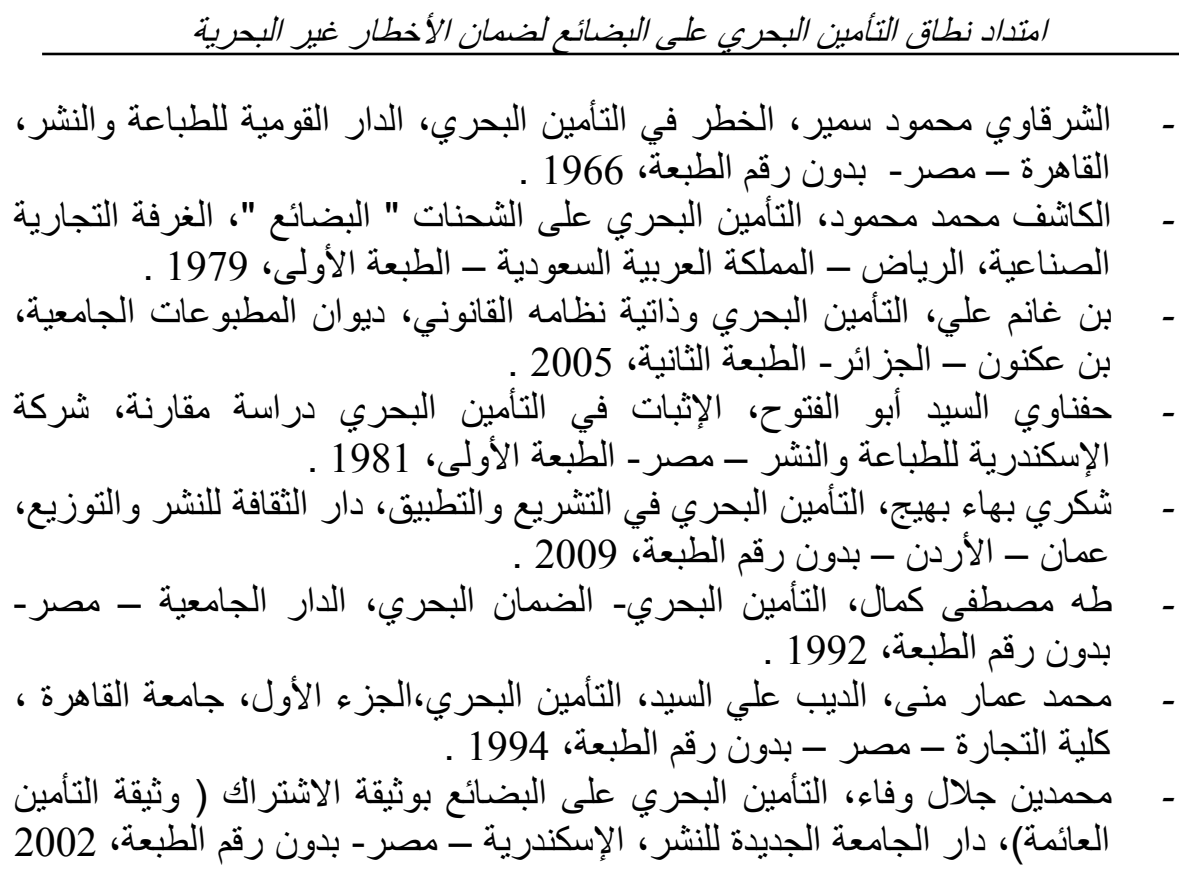

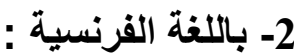

- BENFADHEL (O). Les assurances maritimes et transports. Article publié dans la revue mensuelle algérienne " le Phare » $\mathrm{n}^{\circ} 6$. Octobre 1999.

- BENFADHEL (O). L'assurance transport de magasin à magasin. Article publié dans la revue mensuelle algérienne " le Phare » $\mathrm{n}^{\circ} 56$. Décembre 2003.

- Conférence des Nations Unies sur le Commerce et le Développement (CNUCED). Aspects juridiques et documentaires de l'assurance maritime française. Genève. 20 Octobre 1980.

- Conférence des Nations Unies sur le Commerce et le Développement (CNUCED). Clauses types de la CNUCED relative à l'assurance maritime des corps de navires et marchandises. New York. 1989.

- La Compagnie Algérienne des Assurances (CAAT). Séminaire sur le transport maritime. Alger. 2006.

- LAMBERT-FAIVRE (Y). Les assurances des entreprises. Dalloz. Paris - France -2 è me édition. 1986.

- Les conditions générales de la Compagnie Algérienne des Assurances (CAAT). Police d'assurance maritime sur facultés. Visa M.F.N ${ }^{\circ} 15 \mathrm{du}$ 16/03/1998.

- MARQ (J.P). Risques et assurances transports. Edition l'argus de l'assurance. Pris - France - Sans Numéro d'édition 2003. 